\title{
A Cross Sectional Study on the Preference for Natural Childbirth among Pre-Marital Women in the Greater Kuala Lumpur, Malaysia
}

\author{
Rosnah Sutan*, Loo Carmen, Lianawati Idayu Mohd Azhar, Dazuin Maryam Sabardin, Hanisah Nasuha Mohd \\ Sharif and Karanjot Singh Dashindar Singh \\ Department of Community Health, Universiti Kebangsaan Malaysia Medical Centre, Malaysia
}

Submission: May 21, 2018; Published: June 06, 2018

"Corresponding author: Rosnah Sutan, Department of Community Health, Faculty of Medicine, Universiti Kebangsaan Malaysia Medical Centre, Jalan Yaakoblatiff, Bandar Tun Razak Cheras, 40150 Kuala Lumpur, Malaysia, Tel: +60391455896; Fax: +603-91456670; Email: rosnah_sutan@yahoo.com/ rosnah.sutan@ppukm.ukm.edu.my

\begin{abstract}
Natural childbirth has raised concerns among healthcare providers on its safety and outcomes since many decades ago. Aiming for a safer birth and healthy baby is a dream among all expectant mothers to be. The aim of this study is to measure the prevalence of inclination towards natural childbirth among pre-marital women. A cross-sectional study using guided self-administered questionnaire conducted in Kuala Lumpur from June-August 2016. There were 360 respondents proportionately recruited from premarital courses and the office of the Registrar of Marriages, National Registration Department of Kuala Lumpur. The selection criteria for the study were Malaysian, premarital stage, reproductive age, understood English or Malay Language. Questionnaires distributed after the selected study sites gave permission, and respondents consented. The natural birth defined as childbirth without medical intervention. Majority of respondents (94\%) were aware on natural birth. Nearly half of the total respondents (40.5\%) preferred natural childbirth as the method of delivery, $59.5 \%$ preferred medical intervention. Bivariate analysis showed that strong individual perception of natural childbirth and strong family influences factors (p-value $<0.05$ ) determining an inclination towards natural childbirth. Socio-demographic factors were not significant to preference for natural birth. Maternal health information seeking intervention needs to enhance raising public awareness on safe motherhood, and promote health information on choosing the right birth method. Providing premarital course is an alternative way to disseminate the right information to promote safe childbirth to women of reproductive age.
\end{abstract}

Keywords: Natural childbirth; Unassisted birth; Safe motherhood; Family influence

Abbreviations: WHO: World Health Organization; RM: Ringgit Malaysia; SDG: Sustainable Development Goals

\section{Introduction}

Recently there is an increasing trend of women choosing support other than medical intervention during labour, raising public health issues in both developed and developing countries [1]. Legislature is important to guard our population safety and health [1]. Scientific evidence helps legis late the procedure of childbirth in some countries [1]. Natural childbirth is defined as "women preparing for the birth of their babies, confident in their own ability to give birth, being willing to feel contractions, and finding comfort in response to what they are feeling" [2]. Natural childbirth is defined in the dictionary as "a system of managing childbirth in which the mother receives preparatory education in order to remain conscious and assist in delivery with minimal or no use of drugs or anaesthetics" [3]. The endorsed Joint Policy Statement on normal childbirth stated that "childbirth is considered natural childbirth if there is little or no human intervention" [4]. The World Health Organization (2004) defined skilled birth attendants as "accredited health professionals such as midwife, doctor or nurse who are trained to proficiency in the skills needed to manage normal (uncomplicated) pregnancies, childbirth and immediate post-natal period, and in the identification, management and referral of complications in women and newborns" [5]. Natural childbirth was emphasised since 1950s in the domain of women's autonomy [6].

The concept of natural childbirth originated from Reid's [7] in an attempt to minimize medical intervention, using nonanaesthetic medications and eliminating surgical interventions such as episiotomies, forceps and ventouse deliveries and caesarean sections. Many techniques are now available to ease the mother's pain, taught by childbirth educators. Common methods to find comfort from labour pain include the Bradley way, water 
birth, hypnobirth, Lamaze, and doulas [8,9]. Provision of social support from family, friends and partners helps in strengthening pregnant mothers' inner drive during childbirth. It helps women in labour to have peace of mind that will ease delivery without requiring unnecessary medical intervention. Regan et al. (2013) found that $65.4 \%$ of women had the intention to have natural childbirth, followed by $17.3 \%$ who preferred vaginal birth with analgesia [10]. The rest were women who were undecided $(10.8 \%)$, open to natural birth $(3.8 \%)$ and open to vaginal birth with analgesia $(2.7 \%)[10]$.

Many active websites describing natural birth services are from developed countries such as the United States, United Kingdom, Canada and Australia. However, the websites did not clearly state whether the national health department certifies their services. The websites incorporated the importance of social support during childbirth to relieve pain and ease delivery drug-free. This concept of natural childbirth has spread globally because of the dissatisfaction with birth management in the hospital or clinic setting that has led to inability to create positive birth experiences [1,11-13].

To date, there is a limited amount of research even in developing countries to determine women's perception of childbirth. A systematic review that was published recently documented that the experiences of mistreatments included verbal abuse, lack of informed consent and confidentiality, inadequate physical examination and procedures, loss of autonomy, lack of privacy, stigma and discrimination, neglect and abandonment [12]. The World Health Organization has highlighted the importance of childbirth mistreatment, and proposed to organize more advocacies and dialogues to promulgate safe and respectful care during childbirth [14]. Therefore, women may choose their preference in order to remain comfortable throughout childbirth. Many advertisements on promoting natural birth as a choice is available in social media. Without proper guidance, this can be a source of concern.

Natural childbirth seems to have created a heated debate among Malaysians recently after two tragic maternal deaths that occurred in Greater Kuala Lumpur [15]. Some Malaysian women nowadays opt for homebirths in the presence of a doula or trained companion despite having access to local hospitals [16]. Malaysian doulas are not considered qualified midwives according to the Midwifery Act 1966 [15]. A doula can be an older woman with experience in the family, who can help make decisions and provide social support during childbirth. Malaysian mothers who wish to have natural births often do not seek professional medical consultation [17-19]. These women often attend seminars conducted by pro-natural birth groups, do their own research on the internet or social media, or seek advice from mothers who have gone through natural birth without proper medical supervision. The majority of these women are those with a formal education who should be concerned about the necessity of booking their pregnancies at healthcare clinics and plan for safe delivery [20].
To date, natural birth is not practiced in government hospitals or health premises under the Ministry of Health Malaysia (MOH), as no healthcare personnel is trained in natural childbirth [15]. The MOH has clearly stated the role of healthcare providers when facing pregnant mothers who request for natural birthat home [15]. The $\mathrm{MOH}$ does allow for childbirth at home for low risk mothers after screening by healthcare personnel, with appropriate management planned according to the colour coding system for risk assessment level $[15,21,22]$. The two tragic cases of maternal death secondary to post-partum haemorrhage were reported to have occurred in an unassisted home birth setting $[15,23]$. In these homebirth cases reported in Malaysia no assistance was requested from any healthcare personnel during labour. Both cases were assisted by a doula who was not trained to recognize danger signs of emergency and complication. Such homebirths without monitoring by healthcare personnel were risky both from the maternal and neonatal perspectives [18]. A Cochrane Review highlighted the problem of using the existing trial to compare between planned home birth and planned hospital birth, as the number did not reflect the real situation for generalisation, and policy making on childbirth safety and risks [24]. A study conducted in the United States in 2006 concluded that" home births are associated with a number of less frequent adverse perinatal outcomes at the expense of more frequent abnormal labours and low 5-minute Apgar scores" [25]. However, the conclusion of that study does not apply to the situation in Malaysia and many developing countries due to the different level of availability of facilities and accessibility to trained healthcare personnel.

Reducing maternal mortality is one of the associated targets to be achieved under Sustainable Development Goals by 2030 under target 3.1 of goal 3 [26]. There are two indicators to be achieved: maternal mortality ratio and proportion of births attended by skilled health personnel. In Malaysia, there has been a significant reduction in maternal mortality ratio compared to two decades ago [20]. However, since 2000, Malaysia has been facing the challenge to sustain or further reduce the maternal mortality ratio. Although at a low level, the maternal mortality ratio has been stagnant, and only shows little decline from 27.9 per 100,000 live births in 2005 to 26.1 per 100,000 live births in 2010 and 25.2 per 100,000 live births in 2013 [20]. The main causes of maternal mortality are medical conditions, postpartum haemorrhage, obstetric embolism and hypertensive disorders in pregnancy [20]. Starting from July 2012, the Malaysian Director General of Health has given priority to this issue. The measures taken include having monthly national meetings, case presentations and discussions, and remedial actions like improving quality of care [20-23]. By improving the health care system for pregnant women, it has managed to reduce catastrophic complications that lead to maternal and perinatal death [16,22-23].

However, the two reported cases of maternal death due to postpartum haemorrhage from unassisted home birth in 
Malaysia [16-19] have raised an alert among the public and private healthcare providers in Malaysia. Home birth has been occurring in certain rural areas in Malaysia. It has been practiced by traditional midwives and untrained birth attendants for many decades, before the existence of modern medical facilities and hospitals. Since the quality of the healthcare system in Malaysia has improved evolutionally [20,26], it piques the interest among the researchers on the reasons behind the choice of natural childbirth, outside a hospital setting when good quality healthcare service is provided by the government. Since 1960, the performances of health indicators in Malaysia have improved dramatically due to the purchase of more technological equipment and set up of better health facilities, with healthcare personnel that are equipped with competent skills and modern medical practices. Many births occurred outside hospitals before Malaysia's independence, however, by 1990, only 5\% of births occurred outside hospitals [27].

Today, alternative and complementary services are mushrooming. Many natural childbirth methods, programs, and classes are available to help pregnant mothers prepare to give birth without pain or medications in Malaysia, especially in Greater Kuala Lumpur. Many Malaysian women, especially those with formal education, raised concerns on natural birth as reported on social media [16-19], even though good healthcare facilities are accessible within 5 to $10 \mathrm{~km}$ with good transport and communication [20]. However, there has been no study on natural childbirth in Malaysia and thus, no national statistics available. A majority of the studies were conducted in developed countries with a limited number in Asia. A few recent studies concluded that most women desire natural childbirth, and almost all of them are highly educated and have high incomes $[28,29]$. A number of studies revealed other factors that affect women's choice of childbirth method. Among the many factors, autonomy and previous birth experience are the most important
[30]. Mothers feel that childbirth is a natural process and medical interventions are unnecessary [30]. Some mothers had bad birth experiences, feeling that they did not have enough room for movement, their individual wishes were not fulfilled, lack of participation in decision-making or basic comfort [31]. Women's perception of natural childbirth is important as it affects their actions. Uninformed and unassisted homebirths are dangerous. Women might not seek help and advice from medical personnel because they are afraid that their choices might invite discriminations and stigmatizations [32,33]. Knowing their intention on natural childbirth would be useful in helping the healthcare provider deliver maternal care and support to them with better understanding of their concerns, hopes and fears in childbirth. Some pregnant mothers may not utilize government facilities [20] at all, or they attend private facilities only. Promoting safe motherhood through health risk colour coding, home visits and health education are basic services provided to all mothers visiting governmental health facilities [21-22]. Women of reproductive age need to be educated on the importance of safe motherhood. In Malaysia, reproductive health education is incorporated into the Muslim premarital course, which is made compulsory for all prospective Muslim husbands and wives before their marital registration [34]. The Catholics do provide marriage preparation courses, but they are mandatory only for couples who intend to get married at churches in Greater Kuala Lumpur [35]. This is the best time to empower reproductively healthy couples with knowledge on safe pregnancy and childbirth. Therefore, the present study aims to find out the demographic characteristics of women who intend to have natural childbirth, and its associated factors like family or peer influence among unmarried women of reproductive age at the premarital stage. This study hypothesised that family influence, peer influence, women of a younger age, higher level of education, and higher monthly income are factors of having a higher intention for natural childbirth.

\section{Materials and Methods}

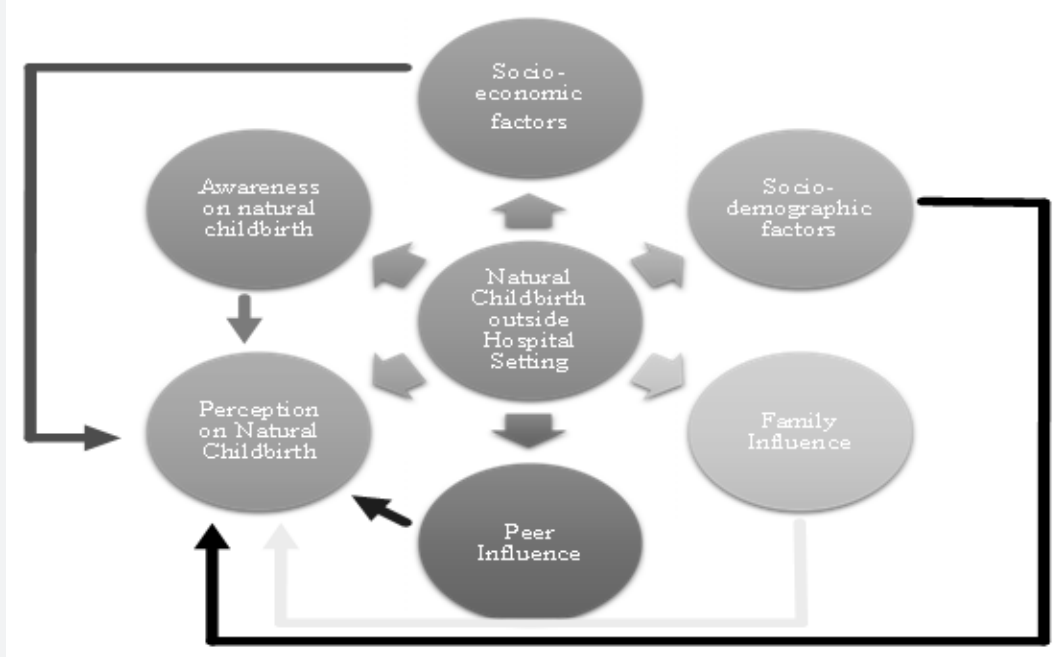

Figure 1: Conceptual framework of present study. 
There is currently no standard questionnaire available to measure the prevalence and determinants of intention for a natural birth that can be identified in the literature. An online search and review of 50 journals that are related to the present research using meshwork terms such as: "alternative birth", "unassisted birth", "natural childbirth", and "homebirth" through PROQUEST and MEDLINE were conducted in the first phase. This review found that the contributing factors in choosing the method of childbirth include: socio-economic factors, socio-demographic factors, religion, family influence, peer influence and perception. Based on these findings, a conceptual framework for the present study is constructed, as shown in Figure 1. A questionnaire was designed based on the conceptual framework.

A cross-sectional study using a population-based approach was carried out in Greater Kuala Lumpur. Greater Kuala Lumpur was purposely chosen as the study area to represent the most populated area in Malaysia, with diverse population characteristics, and residential houses located in areas with easy access to both private and government healthcare premises. Pro natural birthing groups usually target big cities like Kuala Lumpur where most people can afford to attend classes, and are educated enough to access the social media or internet to get to their services or products. The two tragic maternal deaths occurred in Greater Kuala Lumpur. Sample size was determined using the Kish L. formula [36], by referring to the prevalence value from the research entitled" Choice? Factors that influence women's decision making for childbirth" [10]. The prevalence of women who preferred natural childbirth from the study was $65.4 \%$ or 0.654 . Using a confidence interval of $95 \%$ with $\mathrm{Z} 0.95=1.96$ from the normal distribution table, and an absolute precision of $5 \%(0.05)$, the sample size was calculated as shown below.

Sample size, $\mathrm{n}=(1.96) 2(0.654(1-0.654) / 0.052)=348$

An additional $10 \%$ of the calculated sample size was added, leading to a total sample size of 383. The questionnaires were distributed through premarital courses registration at a mosque, a church and through marital registration in the National Registration Department from June-August 2016. As Malaysia has multiple ethnic groups (Malay, Chinese and Indian), the samples were selected proportionately according to the ethic distribution. All respondents were single Malaysian women in their reproductive age who were attending the premarital counseling or performing their marital registrations, and understood English or Malay languages. Those who reported having underlying medical illnesses were excluded. A brief explanation on the purpose of the present research was given, and written consents were acquired from the respondents before filling up the questionnaires.

The definitions of the dependent variablesi.e. Childbirth methods used in the present study were as follows:

a. Natural birth: A system of managing childbirth in which the mother receives preparatory education in order to remain conscious and assist in delivery with minimal or no use of drugs or anaesthetics [3].

b. Medicated birth: Childbirth with the use of medication to dull or eliminate the pain of labor.

c. Analgesic birth: Childbirth where analgesic drugs are given to relieve pain intravenously, through an intravenous drip that is "dripped" slowly through a needle (catheter) that has been inserted in veins, epidural, pudendal block or general anesthesia following cesarean section.

For statistical analysis, the childbirth methods were regrouped into natural and other methods (medicated and analgesic birth) in bivariate analysis. The independent variables were socio-economic factors, socio-demographic factors, family influence, peer influence, awareness of natural childbirth, perception on natural childbirth, and the source of knowledge on natural childbirth.

Data was analyzed using Statistical Package for the Social Sciences (SPSS) Version 20.0. Descriptive analysis based on central tendency (mean, median, mode), and bivariate analysis using Chi Square test for categorical data were performed. A guided self-administered questionnaire that contains 25 items were used. The respondents answered the questionnaire at the beginning of the premarital course class for the Muslims in the mosque, and Catholics in the church, while other ethnics were approached at the National Registration Department at the point of marriage registration. Information sheets were given together with the questionnaires. The researchers were around during the answering session, for further clarification of unclear questions or items on the questionnaire. A prior pre-test of the questionnaire was done to test its face validity in terms of language appropriateness. Ethics approval was earlier obtained from the Universiti Kebangsaan Malaysia Research Ethics Committee. Permission from the managements of the study sites were obtained prior to the data collection period.

\section{Results}

Table 1: Socio demographic description of the respondents and their intention for natural childbirth $(n=360)$.

\begin{tabular}{|c|c|c|}
\hline Characteristics & Natural Birthing $n=148(\%)$ & Other Methods $\mathbf{n = 2 1 2}(\%)$ \\
\hline \multicolumn{3}{|c|}{ Age } \\
\hline$<18$ years old & $1(50.0 \%)$ & $1(50.0 \%)$ \\
\hline $18-29$ years old & $116(40.4 \%)$ & $171(59.6 \%)$ \\
\hline 30-39 years old & $25(44.6 \%)$ & 31 (55.4\%) \\
\hline
\end{tabular}


Journal of Gynecology and Women's Health

\begin{tabular}{|c|c|c|}
\hline$\geq 40$ years old & $6(40.0 \%)$ & $9(60.0 \%)$ \\
\hline \multicolumn{3}{|c|}{ Race } \\
\hline Malay & $84(38.7 \%)$ & $133(61.3 \%)$ \\
\hline Chinese & $31(37.8 \%)$ & $51(62.2 \%)$ \\
\hline Indian & $21(50.0 \%)$ & $21(50.0 \%)$ \\
\hline Others & $7(63.6 \%)$ & $4(36.4 \%)$ \\
\hline \multicolumn{3}{|c|}{ Religion } \\
\hline Muslim & $86(39.1 \%)$ & $134(60.9 \%)$ \\
\hline Buddhist & $16(42.1 \%)$ & $22(57.9 \%)$ \\
\hline Hindu & $24(43.6 \%)$ & $31(56.4 \%)$ \\
\hline Christian & $21(46.7 \%)$ & $24(53.3 \%)$ \\
\hline Others & $1(25.0 \%)$ & $3(75.0 \%)$ \\
\hline \multicolumn{3}{|c|}{ Education Level } \\
\hline No formal education & $0(0.0 \%)$ & $0(0.0 \%)$ \\
\hline Primary school & $3(60.0 \%)$ & $2(40.0 \%)$ \\
\hline Secondary school & $32(47.1 \%)$ & $36(52.9 \%)$ \\
\hline Certificate or diploma level & $38(35.5 \%)$ & $69(64.5 \%)$ \\
\hline First degree level & $64(40.3 \%)$ & $95(59.7 \%)$ \\
\hline Masters/PhD & $11(47.8 \%)$ & $12(52.2 \%)$ \\
\hline \multicolumn{3}{|c|}{ Occupation } \\
\hline Fulltime worker & $98(44.7 \%)$ & $121(55.3 \%)$ \\
\hline Part time worker & $8(34.8 \%)$ & $15(65.2 \%)$ \\
\hline Not working & $25(38.5 \%)$ & $40(61.5 \%)$ \\
\hline Others & $17(30.9 \%)$ & $38(69.1 \%)$ \\
\hline \multicolumn{3}{|c|}{ Level of Income } \\
\hline Low income $(<\mathrm{RM} 3000)$ & $50(47.2 \%)$ & $56(52.8 \%)$ \\
\hline Middle income (RM3000-7000) & $89(40.5 \%)$ & $131(59.5 \%)$ \\
\hline High income (>RM7000) & $9(25.0 \%)$ & $27(75.0 \%)$ \\
\hline
\end{tabular}

The response rate of our study was 98\% ( $n=360$ samples), and was above the number of the calculated sample size ( $n=348)$. The descriptive analysis of the respondents' socio demography and their preference for natural birth are shown in Table 1. The mean age of the respondents was 22.4 \pm SD 0.558 years and fell within the range of 17-50 years. The majority of the respondents were young adults of 18-29 years old (79.3\%), Malays (60.0\%), Muslims (60.8\%), currently working (66.9\%), with tertiary education (79.8\%) and monthly income above RM3000 (70.7\%).

Table 2 shows the prevalence of awareness, perception, preference and attitude on natural childbirth according to their intention for natural childbirth. We found that $41.1 \%$ of respondents already showed preference for natural childbirth at this premarital stage. In $56 \%$ of respondents, the source of knowledge on childbirth method was from social media, and the least was from healthcare providers (25\%). Figure 2 shows that $34.2 \%$ of premarital women strongly perceived natural childbirth as safe. Table 2 shows the distribution of respondents by preference of childbirth methods based on their awareness, perception, preference and attitude. Among the five choices of different natural childbirth methods, the best known type of natural childbirth was home birth, followed by water birth. The largest source of knowledge on natural childbirth was social media, which included Facebook, Twitter, YouTube, blogs and other websites. The second largest source of information was testimonies from family and friends, followed by printed media such as newspapers, books, magazines and journals. The least source of information was from healthcare providers. Almost half $(41.5 \%)$ of respondents already intended to attempt natural birth and have already heard about the method. A majority of them learnt from testimonies on natural birth. Surprisingly, $56.1 \%$ of them perceived natural childbirth as safe. Those who have the intention for natural childbirth preferred to have their delivery method to be available in hospitals (39.6\%), clinics (57.1\%) and low risk birthing centres (66.7\%). However, 71.4\% of them still preferred to have natural childbirth at home. There were $41.3 \%$ who already intended to have natural birth and have the desire to seek advice from healthcare providers on natural birth method. 


\section{Journal of Gynecology and Women's Health}

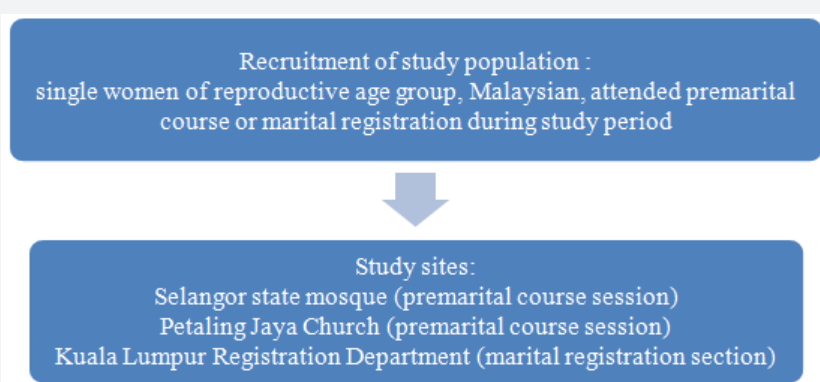

Guided self administered questionaire distributed after consent taken

Data analysis

Figure 2: Methodological framework of the present study.

Table 2: Awareness, perception, preference and attitude on natural childbirth according to their intention for natural childbirth.

\begin{tabular}{|c|c|c|}
\hline Characteristics & Natural Birthing N = $148(\%)$ & Other Methods N = $212(\%)$ \\
\hline \multicolumn{3}{|c|}{ Have Heard about Natural Birth } \\
\hline Yes & $142(41.4 \%)$ & $201(58.6 \%)$ \\
\hline No & $6(35.3 \%)$ & $11(64.7 \%)$ \\
\hline \multicolumn{3}{|c|}{ Awareness Based on Type of Natural Birth } \\
\hline Home birth & $112(38.6 \%)$ & $178(61.4 \%)$ \\
\hline Water birth & $89(35.7 \%)$ & $160(64.3 \%)$ \\
\hline Acupuncture & $1(8.3 \%)$ & $11(91.7 \%)$ \\
\hline Hypnosis & $6(50.0 \%)$ & $6(50.0 \%)$ \\
\hline Lotus birth & $28(38.4 \%)$ & $45(61.6 \%)$ \\
\hline Don't know & $12(54.5 \%)$ & $10(45.5 \%)$ \\
\hline \multicolumn{3}{|c|}{ Source of Knowledge on Natural Birth } \\
\hline Testimonies & $92(51.7 \%)$ & $86(48.3 \%)$ \\
\hline $\begin{array}{c}\text { Written references (Books, Magazine, } \\
\text { Journals) }\end{array}$ & $56(33.9 \%)$ & $109(66.1 \%)$ \\
\hline Healthcare providers & $28(30.4 \%)$ & $64(69.6 \%)$ \\
\hline $\begin{array}{c}\text { Social media (Facebook, Youtube, Blogs, } \\
\text { Twitter) }\end{array}$ & $70(34.5 \%)$ & $133(65.5 \%)$ \\
\hline \multicolumn{3}{|c|}{ Strongly Perceived that Natural Birth is Safe } \\
\hline Yes & $69(56.1 \%)$ & $54(43.9 \%)$ \\
\hline No & $79(33.2 \%)$ & $158(66.8 \%)$ \\
\hline \multicolumn{3}{|c|}{ Preference of Own Childbirth by Place of Delivery } \\
\hline Hospital & $135(39.6 \%)$ & $206(60.4 \%)$ \\
\hline Clinic & $4(57.1 \%)$ & $3(42.9 \%)$ \\
\hline Low risk birthing centre & $4(66.7 \%)$ & $2(33.3 \%)$ \\
\hline Home & $5(71.4 \%)$ & $2(28.6 \%)$ \\
\hline Others & $0(0.0 \%)$ & $1(100.0 \%)$ \\
\hline \multicolumn{3}{|c|}{ Preference of Own Childbirth by Type of Delivery } \\
\hline Natural birth & $148(100.0 \%)$ & $0(0.0 \%)$ \\
\hline Medication birth & $0(0.0 \%)$ & $179(100.0 \%)$ \\
\hline Analgesic birth & $0(0.0 \%)$ & $33(100.0 \%)$ \\
\hline
\end{tabular}




\section{Journal of Gynecology and Women's Health}

\begin{tabular}{|c|c|c|}
\hline \multicolumn{3}{|c|}{ Desire to Seek Advice from Healthcare Provider Regarding Natural Childbirth } \\
\hline Yes & $145(41.3 \%)$ & $206(58.7 \%)$ \\
\hline No & $3(30.0 \%)$ & $7(70.0 \%)$ \\
\hline
\end{tabular}

Table 3 shows the distribution of family and peer influence on natural birth. More than half $(59.1 \%)$ of the respondents, who intended to have natural birth, have family members who have experienced natural birth, and $51.9 \%$ have peers who have experienced natural birth. Half of them who intended to have natural birth were actually interested to know more about

natural birth, and preferred to get information from family members' experiences. Table 4 shows the bivariate analysis of the respondents by their intended mode of childbirth. Family influence seems to be significant for premarital women among other factors. Other significant determinants were perception of safety of natural childbirth, and the source of knowledge.

Table 3: Family and peer influence on the preference of childbirth method and the preference of source of childbirth information.

\begin{tabular}{|c|c|c|}
\hline Characteristics & Natural Birthing N (\%) & Other Methods N (\%) \\
\hline \multicolumn{3}{|c|}{ Family Influence } \\
\hline \multicolumn{3}{|c|}{ Had family members who experienced natural childbirth(n=362) } \\
\hline Yes & $52(59.1 \%)$ & $36(40.9 \%)$ \\
\hline No & $96(35.0 \%)$ & $178(65.0 \%)$ \\
\hline \multicolumn{3}{|c|}{ If YES, do you agree? ( $n=310)$} \\
\hline Agree & $43(59.7 \%)$ & $29(40.3 \%)$ \\
\hline Disagree & $39(34.8 \%)$ & $73(65.2 \%)$ \\
\hline Unsure & $49(38.9 \%)$ & $77(61.1 \%)$ \\
\hline \multicolumn{3}{|c|}{ If YES, Will They Influence You for Natural Childbirth?(N=348) } \\
\hline Yes & $74(62.2 \%)$ & $45(37.8 \%)$ \\
\hline No & $69(30.1 \%)$ & $160(69.9 \%)$ \\
\hline \multicolumn{3}{|c|}{ If YES, Are you Interested to Know More about Natural Birth?(N=346) } \\
\hline Yes & $109(48.9 \%)$ & $114(51.1 \%)$ \\
\hline No & $35(28.5 \%)$ & $88(71.5 \%)$ \\
\hline \multicolumn{3}{|c|}{ Peer Influence } \\
\hline \multicolumn{3}{|c|}{ Had peers who experienced natural childbirth. $(\mathrm{n}=361)$} \\
\hline Yes & $28(51.9 \%)$ & $26(48.1 \%)$ \\
\hline No & $119(38.8 \%)$ & $188(61.2 \%)$ \\
\hline \multicolumn{3}{|c|}{ If YES, do you agree?(n=301) } \\
\hline Agree & $34(54.8 \%)$ & $28(45.2 \%)$ \\
\hline Disagree & $46(38.7 \%)$ & $73(61.3 \%)$ \\
\hline Unsure & $44(36.7 \%)$ & $76(63.3 \%)$ \\
\hline \multicolumn{3}{|c|}{ If YES, Will They Influence You for Natural Childbirth?(N=341) } \\
\hline Yes & $61(60.4 \%)$ & $40(39.6 \%)$ \\
\hline No & $82(34.2 \%)$ & $158(65.8 \%)$ \\
\hline \multicolumn{3}{|c|}{ If YES, Are You Interested to Know More about Natural Birth?(N=341) } \\
\hline Yes & $101(50.5 \%)$ & $99(49.5 \%)$ \\
\hline No & $43(30.5 \%)$ & $98(69.5 \%)$ \\
\hline \multicolumn{3}{|c|}{ Preference of Source of Childbirth Information } \\
\hline Internet $(\mathrm{n}=228)$ & $92(40.4 \%)$ & $136(59.6 \%)$ \\
\hline Books/Magazines (n=138) & $53(38.4 \%)$ & $85(61.6 \%)$ \\
\hline Healthcare providers $(\mathrm{n}=212)$ & $77(36.3 \%)$ & $135(63.7 \%)$ \\
\hline Newspaper $(n=43)$ & $14(32.6 \%)$ & $29(67.4 \%)$ \\
\hline Experienced family members $(\mathrm{n}=162)$ & $73(45.1 \%)$ & $89(54.9 \%)$ \\
\hline Experienced friends $(\mathrm{n}=90)$ & $39(43.3 \%)$ & $51(56.7 \%)$ \\
\hline
\end{tabular}




\section{Journal of Gynecology and Women's Health}

Table 4: Bivariate analysis on the determinants of natural childbirth according to the intention for natural childbirth among the respondents.

\begin{tabular}{|c|c|c|c|c|}
\hline Characteristics & Natural Birthing N (\%) & Other Methods N (\%) & $\mathrm{X}^{2}$ & P-Value \\
\hline \multicolumn{5}{|c|}{ Age } \\
\hline Youth $(<24$ year old $)$ & $73(40.6 \%)$ & 107 (59.4\%) & 2.711 & 0.258 \\
\hline Young adult (25-44 year old) & $70(40.5 \%)$ & $103(59.5 \%)$ & & \\
\hline Senior adult ( 45 year -) & $5(71.4 \%)$ & $2(28.6 \%)$ & & \\
\hline \multicolumn{5}{|c|}{ Race } \\
\hline Malay & $84(38.7 \%)$ & $133(61.3 \%)$ & 1.06 & 0.303 \\
\hline Non Malays & $64(44.1 \%)$ & $81(55.9 \%)$ & & \\
\hline \multicolumn{5}{|c|}{ Religion } \\
\hline Muslim & $86(39.1 \%)$ & $134(60.9 \%)$ & 0.746 & 0.388 \\
\hline Non-Muslim & $62(43.7 \%)$ & $80(56.3 \%)$ & & \\
\hline \multicolumn{5}{|c|}{ Education Level } \\
\hline $\begin{array}{l}\text { Primary and secondary } \\
\text { education }\end{array}$ & $35(47.9 \%)$ & $38(52.1 \%)$ & 1.886 & 0.17 \\
\hline Tertiary education & $113(39.1 \%)$ & $176(60.9 \%)$ & & \\
\hline \multicolumn{5}{|c|}{ Occupation } \\
\hline Working & $106(43.8 \%)$ & $136(56.2 \%)$ & 2.571 & 0.109 \\
\hline Unemployed & $42(35.0 \%)$ & $78(65.0 \%)$ & & \\
\hline \multicolumn{5}{|c|}{ Level of Income } \\
\hline Low income $(<3000)$ & $50(47.2 \%)$ & $56(52.8 \%)$ & & \\
\hline Middle income (3000-7000) & $89(40.5 \%)$ & $131(59.5 \%)$ & 5.508 & 0.064 \\
\hline High income (>7000) & $9(25.0 \%)$ & $27(75.0 \%)$ & & \\
\hline \multicolumn{5}{|c|}{ Have Heard about Natural Birth } \\
\hline Yes & $142(41.4 \%)$ & $201(58.6 \%)$ & 0.249 & 0.618 \\
\hline No & $6(35.3 \%)$ & $11(64.7 \%)$ & & \\
\hline \multicolumn{5}{|c|}{ Source of Knowledge on Natural Birth } \\
\hline Healthcare providers & $28(30.4 \%)$ & $64(69.6 \%)$ & 5.327 & 0.021 \\
\hline $\begin{array}{c}\text { Non healthcare providers: } \\
\text { • Testimonies (Family/Friends) } \\
\text { • Written resources } \\
\text { • Online resources }\end{array}$ & $\begin{array}{l}92(51.7 \%) \\
56(33.9 \%) \\
70(34.5 \%)\end{array}$ & $\begin{array}{c}86(48.3 \%) \\
109(66.1 \%) \\
133(65.5 \%)\end{array}$ & $\begin{array}{c}18.034 \\
5.671 \\
7.34\end{array}$ & $\begin{array}{c}<0.001 \\
0.017\end{array}$ \\
\hline \multicolumn{5}{|c|}{ Perception That Natural Birth is Safe } \\
\hline Yes & $69(56.1 \%)$ & $54(43.9 \%)$ & 17.587 & $<0.001$ \\
\hline No & $79(33.2 \%)$ & $159(66.8 \%)$ & & \\
\hline \multicolumn{5}{|c|}{ Preference of Own Childbirth by Place of Delivery } \\
\hline Healthcare facilities & $143(40.4 \%)$ & $211(59.6 \%)$ & 1.582 & 0.209 \\
\hline Home / others & $5(62.5 \%)$ & $3(37.5 \%)$ & & \\
\hline \multicolumn{5}{|c|}{ Desire to Seek Advice from Healthcare Providers Regarding Natural Childbirth } \\
\hline Yes & $145(41.3 \%)$ & $206(58.7 \%)$ & 0.514 & 0.473 \\
\hline No & $3(30.0 \%)$ & $7(70.0 \%)$ & & \\
\hline \multicolumn{5}{|c|}{ Had Family Members Who Experienced Natural Childbirth } \\
\hline Yes & $52(59.1 \%)$ & $36(40.9 \%)$ & 15.946 & $<0.001$ \\
\hline No & $96(35.0 \%)$ & $178(65.0 \%)$ & & \\
\hline \multicolumn{5}{|c|}{ Had Peers Who Experienced Natural Childbirth } \\
\hline Yes & $28(51.9 \%)$ & $26(48.1 \%)$ & 3.26 & 0.071 \\
\hline No & $119(38.8 \%)$ & $188(61.2 \%)$ & & \\
\hline
\end{tabular}




\section{Discussion}

Based on our review of online journals from PROQUEST and MEDLINE database, there are six factors that have been commonly discussed that contribute to natural childbirth, but only three factors were found significant in the present study: family influence, perception of safety, and source of information. To date, there is no standard definition for natural childbirth. The term "normal birth" has been defined as "birth that is spontaneous in onset, low-riskat the start of labour and remaining so throughout labour and delivery. The infant is born spontaneously, in vertex position between 37 and 42 completed weeks of pregnancy, after which the mother and the infant are in good condition" [15]. The term natural childbirth in the present study refers to labour processes using alternative methods without any form of medical intervention. This study assessed the intended method and place of delivery either at hospitals/clinics or at home. Mansfield [31] mentioned that the term natural childbirth was used in many ways, from hospital births without analgesia to childbirth without any medical intervention [31]. The term is normally used in a narrow sense as well as in a broader way. A broader definition of natural birth is "any approach to medicine that makes an effort to incorporate or work with internal processes of the body" [31,37]. Mansfield [31] mentioned that the term used by Cosan focused more on trusting the nature of childbirth to take its course where terms like "natural", "physiological", and treating childbirth as a "natural body function" were used [31].

The present study is a cross sectional population-based study conducted on premarital women. It was designed to eliminate bias which may be present if the study were conducted among pregnant women who have already decided on their birth plan with their healthcare providers. Surprisingly, the findings show that at the premarital stage, $40.5 \%$ of women were already aware and showed preference for natural childbirth. Family influence wasa strong determinant. Scholars in the United Kingdom, Finland, and the Unites States reported similar findings on the enduring appeal of natural childbirth, as it grew flexible enough to accommodate such interventions as pain relief or induction of labour [33].

Therefore, the public healthcare system should improve on enhancing patients' education to ensure that correct information is delivered to the public through reliable sources. Health education focusing on the family is important for a woman in order to raise awareness on making the right choice of childbirth method. The influence of the social media that challenges the medicalization of childbirth needs to be tackled strategically, through appropriate health information, education and effective communication. The role of family members in giving autonomy of decision to women to choose the right and safe childbirth method is highly encouraged.

Concerns or studies on the efficiency of natural childbirth compared to standard procedures in hospitals need careful interpretation as concluded by Olsen and Clausen [24]. WHO [38] recommended that a trained midwife should be the primary care provider for all deliveries, and by means of 'trained', they must be skilled at assessment and in referral of women who show signs of developing high risk pregnancy or anticipation of birth complications [38]. Delivery in hospitals follows a standard procedure. All deliveries in hospitals and clinics must be attended by skilled personnel as defined by WHO [5]. It is important to educate future mothers about safe childbirth methods, and to attend pre-pregnancy care for screening and counselling. However, most pregnant mothers come to health clinics only when they are in their second trimester, when they are looking for a hospital for delivery. Those who go to private clinics or hospitals are given the option of childbirth method based on their affordability and pregnancy status. Therefore, all women of reproductive age must be educated at the early premarital stage to promote safe delivery plan.

Most women prefers a natural childbirth, and almost all of them are highly educated and have high in comes as depicted in the present study and others [10]. Bad birth experience such as lack of freedom of movement, lack of participation indecisionmaking, and lack of basic comfort, are reported to influence young women who are afraid of hospital procedures [28]. There are certain factors that can be improved or avoided, so that women do not lose confidence and place their trust in the medical team. One of the ways is to empower the women through knowledge and awareness of safe childbirth. The four main sources of information on safe childbirth options are from family members and friends who were attended by trained medical personnel, written sources like childbirth related books, medical journals, and reliable online resources.

Existing evidence have shown that the preference towards delivering at home was mainly to have more comfort and privacy. Studies in low-income countries found that poverty was another important factor that compelled mothers to deliver at home $[28,30]$. Mother's education, household income, number of antenatal visits, and exposure to social media were associated with assisted home delivery by untrained traditional birth attendant [39]. However, the present study did not find any significant association between choice of childbirth and socio demographic factor.

Family influence was found to be a strong determinant of the inclination towards natural birth in this study. An earlier study showed an association between husband's approval of family planning and spousal decision to give birth to her child at a health facility [40]. Another study found that the decision to use traditional birth attendants by women was influenced by family members such as the older sister, parents or husbands [41]. In contrast, a study conducted in Tanzania among women who gave birth in health facilities, and women who gave birth assisted by a traditional birth attendant, stated that family members and their husbands did not influence women in the 
urban community to choose the place of delivery compared to rural sites [42]. Community members perceived the health care professionals as too young and inexperienced compared to traditional birth attendants [42]. However, the women in their study reported that they were influenced by their spouses (40\%) and their midwives (25\%), but not their family and friends on their decision of birthplace [41]. The alternative birth concept initiated as a reaction to the emerging discontentment of the population with hospital birth care [11]. Women tend to choose things that they have experienced [43-45]. The higher level of education among females in the population leads to higher awareness of need for care during labour [40]. The recent study done in Tanzania stated that the implementation and evaluation protocol have benefited as evidence-based for routine monitoring and evaluation activities towards better outcomes based on theory $[43,45]$. The stated theory of change focuses only on the patients, care providers and the healthcare system. However, present study found that the family influence has an important role in decision making too. A large scale study conducted in Australia looking at the different types of delivery settings also have similar findings [46].

With the advancement in technology, there is a wide variety of sources of information on childbirth. There are many websites available on the different methods of childbirth locally and internationally. Books, magazines, newspapers and personal testimonies from family, friends, and even strangers are easily available and accessible to women. Therefore, an effort should be made by the healthcare providers to filter what is the right information, and deliver the correct childbirth information to women of reproductive age as early as during the premarital stage, and also to the families in the community. With better health information for promoting safe childbirth, it is hoped that anxiety on childbirth will be alleviated from the community, and uncertain information will be prevented from reaching the targeted women.

\section{Conclusion}

It is worth noting that a significant number of respondents preferred natural childbirth (40.5\%). Perception and family influence are strong determinants of the preference for natural childbirth. Public health interventions must be strengthen to raise public awareness on safe motherhood and choosing the right childbirth method tailored to a family-centered approach. Integrate the health education related to choice of birth and appropriate care in the premarital counseling course is hope to promote safe mother hood.

\section{Acknowledgment}

This research is approved by Faculty of Medicine, UKM Medical Centre (FF-2016-193) and GUP-2017-115. We acknowledge the Selangor Muslim Department, Petaling Jaya Catholic Church, and the Kuala Lumpur Registration Department for giving permission to carry out data collection at their premises. We also thank Proof Dr Zaleha Abdullah Mahdy, who assisted in proofreading and English language editing of this manuscript.

\section{Ethical and Consent to Participate}

Ethical approval from UKM Research Ethics Committee was obtained (FF-2016-193) prior to data collection, and all participants were informed about this study before giving consent to participate.

\section{Authors' Contributions}

RS designed the study, DMS, KSDS, HNMS, CL and LIMA did the data collection. DMS, KSDS, HNMS analysed the data, RS, CL, LIMA wrote the paper. All authors have reviewed the paper critically, and approved the manuscript.

\section{Author's information}

RS works as a medical lecturer and a Family Health Physician Consultant in UKM. She has working experience in the provision of Maternal and Child Health Services. DMS, KSDS, HNMS, CL and LIMA are final year medical students of UKM who are doing their final project paper.

\section{References}

1. Hodnett ED, Gates S, Hofmeyr GJ, Sakala C (2007) Continuous support for women during childbirth. Cochrane Database of Systematic Reviews 3.

2. Judith LA (2000) Why Natural Childbirth? J Perinat Educ 9(4): 44-46.

3. http://www.merriam-webster.com/dictionary/natural\%20childbirth

4. (2008) Joint Policy Statement on Normal Childbirth. J Obstet Gynaecol Can 30(12): 1163-1165.

5. World Health Organization (2004) Making pregnancy safer: the critical role of the skilled attendant: a joint statement by WHO, ICM and FIGO.

6. Leggitt K (2016) How Has Childbirth Changed in This Century?

7. (1994) Read GD: Childbirth Without Fear. New York, USA.

8. McCutcheon S. Natural Childbirth the Bradley Way: Revised Edition.

9. Datta, Sanjay, Kodali, Bhavani S, Segal, et al. (2006) Obstetric Anesthesia Handbook. Springer Science + Business Media, LLC.

10. Regan M, McElroy KG, Moore K (2013) Choice? Factors that influence women's decision making for childbirth. J Perinat Educ 22(3): 171180.

11. Eberhard J, Geissbühler V (2000) Influence of alternative birth methods on traditional birth management. Fetal Diagnosis Therapy 15(5): 283290.

12. Bohren MA, Vogel JP, Hunter EC, Lutsiv O, Makh SK, et al. (2015) The Mistreatment of Women during Childbirth in Health Facilities Globally: A Mixed-Methods Systematic Review. PLoS Med 12(6): e1001847.

13. Bowser D, Hill K (2010) Exploring evidence for disrespect and abuse in facility-based childbirth: report of a landscape analysis. USAID, Washington DC, USA, pp. 1-57.

14. World Health Organization (2014) The prevention and elimination of disrespect and abuse during facility-based childbirth: WHO statement. Geneva, Switzerland.

15. Director General of Health Malaysia (2014) Suratpe keliling Ketua Pengarah Kesihatanbilangan 05 tahun 2014.-Langkah-langkah bagi mempertingkatkan usaha mengurangkan kelahiran tidak selamat, malyasia. 
16. https://www.pressreader.com/malaysia/the-star-malaysiastar2/20170328/282029032061591

17. Mardiana K (2013) A Journey Back in Time: Home Birth. The Malaysian Medical Gazette.

18. Leong SH (2014) Home birth: Weighing the risks. The Star Online.

19. Loh FF (2013) Don't attempt childbirth at home without medical supervision, says expert. The Star Online.

20. MOH Annual Report (2014) Family Health Development Division, Ministry of Health Malaysia.

21. Leny SS, Shuhaila A, Sutan R (2013) Usage Of Home-Based Maternal Health Record In Antenatal Monitoring Among Malaysian Women Attended University Kebangsaan Malaysia Medical Centre Malaysian. Journal of Public Health Medicine 13(1): 1-10.

22. Ravindran J, Shamsuddin K, Selvaraju S (2003) Did we do it right?-An evaluation of the colour coding system for antenatal care in Malaysia. Med J Malaysia 58(1): 37-53.

23. http://mdsr-action.net/case-studies/malaysias-experience-withmaternal-deaths/

24. Olsen 0, Clausen JA. Planned hospital birth versus planned home birth

25. Wax JR, Pinette MG, Cartin A, Blackstone J (2010) Maternal and newborn morbidity by birth facility among selected United States 2006 low-risk births. Am J Obstet Gynecol 202(2): 152.e1-152.e5.

26. http://www.iris.wpro.who.int

27. Othman MZWR, MohdKhalili NM, Esa S, Miskiman N (2011) Demographic Transition in Malaysia: The Changing Roles of Women. $15^{\text {th }}$ Conference of Commonwealth Statisticians, New Delhi, India, p. 7-10.

28. Rachel Z (2011) Why Home Births Are Becoming More Popular. WBUR's Common Health-Reform and Reality.

29. http://www.takingcharge.csh.umn.edu/explore-healing-practices/ holistic-pregnancy-childbirth

30. Chowdury MAH, Hasan MM, Ahmed S, Darwin C, Hassan MS, et al. (2013) Socio-demographic factors associated with home delivery assisted by untrained traditional birth attendant in rural Bangladesh. American Journal of Public Health Research 1(8): 226-230.

31. Mansfield B (2008) The Social Nature of Childbirth. Social Science \& Medicine 66(5): 1084-1094.

32. Tasneem F, Saira A, Shahid M (2008) Psychosocial Determinants of Preferring Home Births. Biomedica 24: 85-88.

33. MacDonald M (2011) The Art of Medicine: The cultural evolution of natural birth. Lancet 378(9789): 373-456.

34. Saidon R, Ishaka AH, Aliasa B, Ismaila FA, MohdArisa S, et al. (2016) Examining Weaknesses in the Governance of Premarital Course for Muslims in Malaysia. The European proceedings of Social and behavioural sciences epSBS, pp. 5-7.

35. http://www.stignatiuspj. Org/catholic-marriage-preparation-course html

36. Kish L (1996) Safe Motherhood: Care in Normal Birth: A Practical Guide. Department of Reproductive Health \& Research (RHR) Geneva: World Health Organization, Survey Sampling, John Wiley \& Sons, Inc, New York, USA.

37. Cosans C (2004) The meaning of natural childbirth. Perspectives in Biology and Medicine 47(2): 266-272.

38. World Health Organization (2002) Promoting Effective Perinatal Care: Essential Antenatal, Perinatal and Postpartum Care. World Health Organization Regional Office for Europe.

39. Atiqul HC, Mehedi H, Sayem A, Charls D, Mohammad SH, et al. (2013) Socio-demographic Factors Associated with Home Delivery Assisted by Untrained Traditional Birth Attendant in Rural Bangladesh. American Journal of Public Health Research 1(8): 226-230.

40. Stephenson R, Baschieri A, Clements S, Hennink M, Madise N, et al. (2006) Contextual Influences on the Use of Health Facilities for Childbirth in Africa. American Journal of Public Health. Am J Public Health 96(1): 84-93.

41. Titaley CR, Hunter CL, Dibley MJ, Heywood P (2010) Why do women still prefer traditional birth attendants and home delivery?: A qualitative study on delivery care services in West Java Province, Indonesia. BMC Pregnancy and Childbirth 10: 43.

42. Pfeiffer C, Mwaipopo R (2013) Delivering at home or in a health facility? Health-seeking behavior of women and the role of traditional birth attendants in Tanzania. BMC Pregnancy and Childbirth 13: 55.

43. Grigg C, Tracy SK, Daellenbach R, Kensington M, Schmied V, et al (2014) An exploration of influences on women's birthplace decisionmaking in New Zealand: a mixed methods prospective cohort within the Evaluating Maternity Units Study. BMC Pregnancy and Childbirth 14: 210.

44. Viisainen K, Gissler M, Raikkonen O, Perala ML, Hemminki E, et al. (1988) Interest in alternative birth settings in Finland. Acta Obstet Gynecol Scand 77(7): 729-735.

45. Ratcliffe H, Sando D, Lyatuu G, Emil F, Mwanyika-Sando M, et al. (2016) Mitigating disrespect and abuse during childbirth in Tanzania: An exploratory study of the effects of two facility-based interventions in a large public hospital. Reproductive Health 13: 79.

46. Steel A, Adams J, Frawley J, Broom A, Sibbritt D, et al. (2015) The characteristics of women who birth at home, in a birth centre or in a hospital labour ward: A study of a nationally representative sample of 1835 pregnant women. Sex Reprod Healthc 6(3): 132-137.

\begin{tabular}{|l|}
\hline \multicolumn{1}{|c|}{ Your next submission with Juniper Publishers } \\
will reach you the below assets \\
- Quality Editorial service \\
- Swift Peer Review \\
- Reprints availability \\
- E-prints Service \\
- Manuscript Podcast for convenient understanding \\
- Global attainment for your research \\
- Manuscript accessibility in different formats \\
( Pdf, E-pub, Full Text, Audio) \\
- Unceasing customer service \\
Track the below URL for one-step submission \\
https://juniperpublishers.com/online-submission.php \\
\hline
\end{tabular}

